\title{
A Study on the Impact of 3D Printing and Artificial Intelligence on Education and Learning Process
}

\author{
Hyunjin Chun (iD \\ School of Arts, Nanjing University of Aeronautics and Astronautics, No. 29 Jiangjun Road, Jiangning District, Nanjing 211106, \\ Jiangsu, China
}

Correspondence should be addressed to Hyunjin Chun; tough4324@naver.com

Received 8 September 2021; Revised 4 November 2021; Accepted 8 November 2021; Published 18 November 2021

Academic Editor: Rahman Ali

Copyright (c) 2021 Hyunjin Chun. This is an open access article distributed under the Creative Commons Attribution License, which permits unrestricted use, distribution, and reproduction in any medium, provided the original work is properly cited.

Artificial intelligence is part of our future and has allowed the creation of truly advanced devices. Now 3D printing technology can also make full use of AI, and with the development of this technology, it is expected to be used in various fields in the era of the Fourth Industrial Revolution. This technology can be used not only in manufacturing but also in various fields such as architecture and medical care and is recognized as an essential technology for future generations. Educating the students about the use and impact of 3D technology is even more important than it was ever; however, not enough research has been conducted on specific teaching methods for 3D printing technology education. This paper, therefore, studies the future education method using 3D printing technology for children. The research method of this study is a qualitative research method in which interviews and participant observation methods are used. This qualitative research method was developed by James P. Spradley, an American cultural anthropologist. The findings of this study are as follows. Children can make products easily by using 3D programs and can develop creativity through this product design process. Based on these results, this paper aims to present the curriculum and teaching methods of $3 \mathrm{D}$ printing that can be practically utilized in public education courses. This education will be a preparatory step for the micro-manufacturing industry in the future. The findings of this study are helpful in developing the courses of future education.

\section{Introduction}

With the development of the Fourth Industrial Revolution, various innovative technologies sprung up and were applied in various sectors. Among these technologies, 3D printing technology is recognized as one that can make tremendous innovative changes in the manufacturing sector. 3D technology is an innovative technology and shall have a great impact on the future society. In addition, 3D printing technology is used in a variety of fields, so familiarity with and understanding of this technology as well as its applications and the expertise in this technology are quite needed. On school level, we need to include 3D technology in the curriculum in order to be able to create the required expertise. Therefore, it is important and necessary to do research on courses about $3 \mathrm{D}$ printing in future public education curriculum. Applying education ideas and concepts to educational materials and courses through educational policies is important for developing students' potential. Limited knowledge is not enough to face the challenges of the modern society, and the learning and creativity of students must be enhanced in order to be able to achieve better problem-solving capabilities in the future [1]. Spatial visualization skills such as creating 3D art and presenting ideas, concepts, and information using such art are extremely valuable in education, industry, business, and other aspects of life. The ability to perceive the visual world accurately and to transform ideas and concepts to visualizations is termed as spatial intelligence, and it leads to better creativity and capability to execute ideas and projects in a much better way [2].

Despite this importance, no significant research has been conducted on the specific curriculum for 3D printing. In light of this, this study analyzes future education using 3D printing operated in various countries. Based on these results, this paper aims to present the curriculum and teaching 
methods of $3 \mathrm{D}$ printing that can be practically utilized in public education courses.

The main contributions of the paper include the following:

(1) We present a detailed overview of the 3D technology, its tools, and applications in various domains.

(2) We present an overview of the STEAM (science, technology, engineering, arts, and mathematics) education and analyze the needs of creativity and problem-solving capabilities in these fields.

(3) Finally, we discuss in detail the use of $3 \mathrm{D}$ printing technology in education sector, the software tools, i.e., the CAD software, a detailed class plan for the curriculum, and the effect of 3D printing education on students' learning process and creativity. These findings can be used as theoretical data for $3 \mathrm{D}$ printing education.

The results of this study can be used as a theoretical basis for developing a systematic curriculum using 3D printing.

\section{Related Work}

Recently, education on 3D printing is becoming important in advanced countries, which requires teachers in public education to be equipped with $3 \mathrm{D}$ printing knowledge and teaching methods. Prior to carrying out these studies, some of the existing 3D printing education studies were studied. Following is a summary of the related work in this field.

Farnicka and Serrano Diaz presented a detailed study of how 3D printing has an impact on creativity building of children in preschool stage. $3 \mathrm{D}$ visualizations allow children to move from theory to practical work and development which has a significant impact on the child's imagination [1].

Tomc and Kočevar presented an extensive study of how three-dimensional art like images and animations has a positive impact on students' learning and improves their creativity. They concluded that 3D art can improve students' spatial visualization skills and is valuable in every field of education and profession. 3D modelling has a very good impact on the qualitative execution of projects. They conducted questionnaire surveys and concluded that the students that study computer $3 \mathrm{D}$ visualizations are more likely to have higher creative and spatial abilities because the creative process is altered by the educational process, one aspect of which is the design process of 3D visualizations [2].

Sung Kwan and Kim developed a variety of fusion contents to use 3D printing and 8 bit MCU base control board which provided specific functions through Arduino [3].

Shang Gu et al. showed the possibility that mathematics, art, and 3D printing can be effectively used to achieve the goals of STEAM education [4].

Keun found that the use of $3 \mathrm{D}$ printing could improve students' outcomes by fabricating real physical models out of their designs [5].

Kug Joo and Suk Rae composed the step-by-step curriculum linkage which combined theory and practice for students to create the well-made final output [6].
Hyung Shin and Mi Ri reviewed various 3D modelling software applications because modelling skill was a prerequisite skill to use $3 \mathrm{D}$ printers and proposed a creative design spiral-based teaching content that can be incorporated in elementary school contexts [7].

Hyo Young and Hyang Eun verified the effectiveness of design education program using $3 \mathrm{D}$ printing for middle school students [8].

By now, most of the existing studies on $3 \mathrm{D}$ printing were from technical perspectives. Some scientists have studied the methodology for 3D printing education. However, there is still a limit to actually applying $3 \mathrm{D}$ printing to the educational field.

\section{Research Method}

This paper studies the future education method using 3D printing. To do this research, theoretical research was first conducted in this paper. The theoretical study analyzed the principle of $3 \mathrm{D}$ printing and the education of $3 \mathrm{D}$ printing. This paper then analyzed the current status of 3D printing education in advanced countries such as the United States and Japan. These analyses were based on various papers, related books, magazines, etc. In addition, apart from research materials, the author of the paper visited an educational institution where $3 \mathrm{D}$ printing education was conducted and interviewed educators and students. We follow a qualitative research method developed by the US cultural anthropologist James P. Spradley, in which interviews and participant observation methods are used. James P. Spradley studied the participant observation method used by cultural anthropologists. The participant observation is divided into six stages including descriptive observation, domain analysis, focused observation, classification analysis, selective observation, and component analysis [9]. Also, this study then analyzes the problems of $3 \mathrm{D}$ printing education in current educational institutions and presents a kind of $3 \mathrm{D}$ printing curriculum that can actually be used by educational institutions. The effect of 3D printing education on these courses is also evaluated and further analyzed. Finally, this study predicts the development direction of 3D printing education in the future.

\section{A Theoretical Study}

4.1. $3 \mathrm{D}$ Printing. 3D printing technology is to create products in a short time by printing three-dimensional digital files (Figure 1). It is similar to the way paper is printed in two dimensions, but it is different since it targets $3 \mathrm{D}$ products. The technology was developed to shorten the time to make prototypes. In general, it takes weeks for a company to produce a prototype after planning and designing the product. However, if the company uses 3D printing technology to produce prototypes, it can complete prototypes in just a few hours. It can also save a lot of money in producing prototypes. In fact, 3D printing technology was created 30 years ago. However, the technology was not popularized due to patent issues. Currently, the patents for $3 \mathrm{D}$ printing technology have expired. Therefore, 3D printing technology 


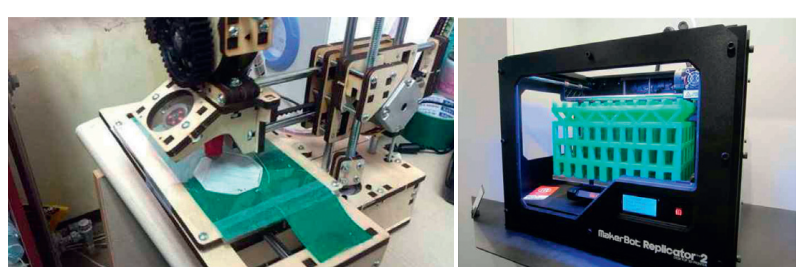

FIGURE 1: 3D printing [4].

could be utilized in various fields. In practice, $3 \mathrm{D}$ printing technology is especially frequently used when cooking food. Also, it is widely used to produce small products such as ornaments. In particular, as $3 \mathrm{D}$ printing technology becomes important in the future, many educational institutions will be interested in 3D printing technology. Therefore, in advanced countries such as the United States and Japan, high schools have introduced 3D printers to teach theories and practices about $3 \mathrm{D}$ printing technology. $3 \mathrm{D}$ printing education is recognized as a very important curriculum in relation to the Fourth Industrial Revolution. The 3D printing technology is expected to contribute to the democratization of manufacturing in the future. In the industrial age, capital could make products. However, the development of 3D printing technology will enable individuals without capital to make products by themselves. These changes are prominent characteristics of the Fourth Industrial Revolution.

4.2. STEAM Education. STEAM education is a talent education program that combines science, technology, engineering, art, and mathematics (Figure 2). It aims at cultivating creative abilities. In the future, as artificial intelligence develops, creative imagination is more important than theoretical knowledge. So, many educational institutions are interested in STEAM education. For this reason, some governments invest heavily in STEAM education. Also, the core of STEAM education is the curriculum that solves real-life problems based on projects. In order to solve these real-life problems, students want to develop problemsolving skills through the process of designing their own solutions. Students can be interested in studying as they solve problems in real life on their own. Also, students need a variety of knowledge to solve real-life problems. Therefore, students need convergence education that requires knowledge of various subjects to solve problems. As such, convergence education is important in STEAM education. In addition, various tools are used in STEAM education. These tools are very important skills in future society. Typical tools include coding, robot, drone, $\mathrm{VR}$, and $3 \mathrm{D}$ printing.

\section{3D Printing Education}

5.1. 3D Printing Education Status. The need for education using 3D printing is increasing. In particular, developed countries such as the UK and Japan provide education using $3 \mathrm{D}$ printing in public education courses. In 3D printing, software learning to create $3 \mathrm{D}$ data is very important. Currently, there are various $3 \mathrm{D}$ software programs for $3 \mathrm{D}$

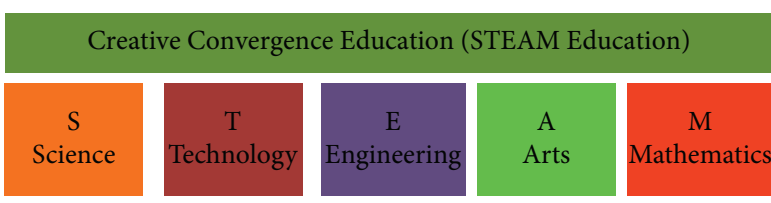

FIGURE 2: STEAM education (the author's figure).

printing. These programs include both complex programs that are for experts and simple programs that elementary school student can easily learn. Typical software programs are Rhino and SketchUp. In fact, these programs are widely used in design and architecture. Recently, 3D software for elementary school students has been widely used by Autodesk's Tinkercad and Autodesk 123D [10]. Most of the education at the current educational institution is focused on CAD software. But as time goes by, new software programs appear. Understanding of software would become unnecessary over time. Therefore, 3D printing education should be a way to develop the ability to make creative ideas when making products.

5.2. CAD Software. In order to use $3 \mathrm{D}$ printing, it is important for students to understand CAD software first (Figure 3). Students should learn theoretical knowledge of CAD software. Based on the theoretical knowledge, students learn practical courses using CAD software. In this course, students practice various examples. Then, students design their own CAD models. The famous CAD software for children's education is Tinkercad. Tinkercad is simple to use. First, learners can use the Tinkercad program through the Internet. The learner then designs the product using the software. Learners save CAD files as 3D SDL files. Finally, users can print $3 \mathrm{D}$ SDL files through a $3 \mathrm{D}$ printer. In addition to Tinkercad, CAD software is also different. Especially, students who are interested in architecture use SketchUp. So, learners can select the most appropriate program according to the purpose of the study and the difficulty level of the program.

5.3. 3D Printing Education Course. 3D printing education course varies depending on schools and teachers. This study aims to present courses that can be practically used in public education among various courses. Course can be divided into several classes (Figure 4). In the first class, teachers give the students theoretical lessons on 3D printing. Theoretical classes include various contents such as characteristics, history, and utilization of $3 \mathrm{D}$ printing. The second class is a theoretical course on CAD software. Teachers teach students how to use CAD software. In addition, teachers show students the results of $3 \mathrm{D}$ printing through various examples. The third class actually shows the product design process through CAD software. Teachers design simple objects, show them to students, and allow students to follow the product design process. Students practice repeatedly as explained. In the fourth class, students do practical projects on their own and try to find these problems in real life. They first put forward problems with their mates. Based on these 


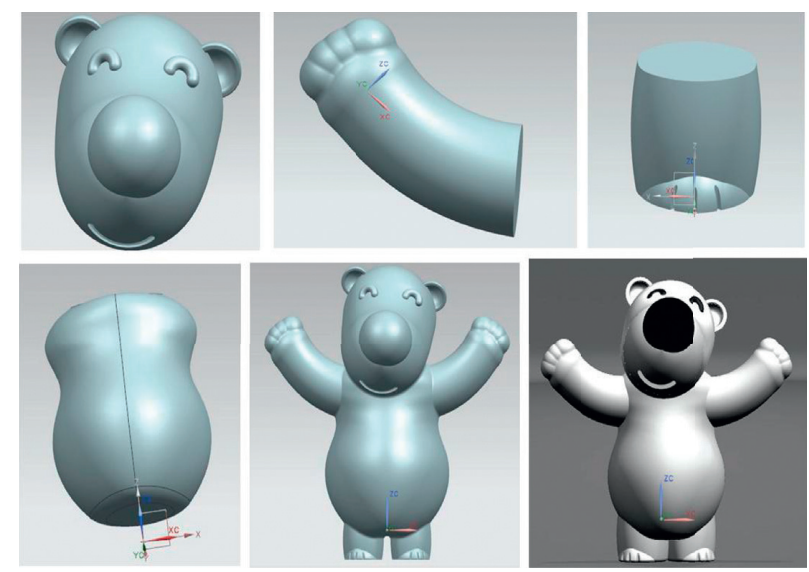

Figure 3: CAD software [5].
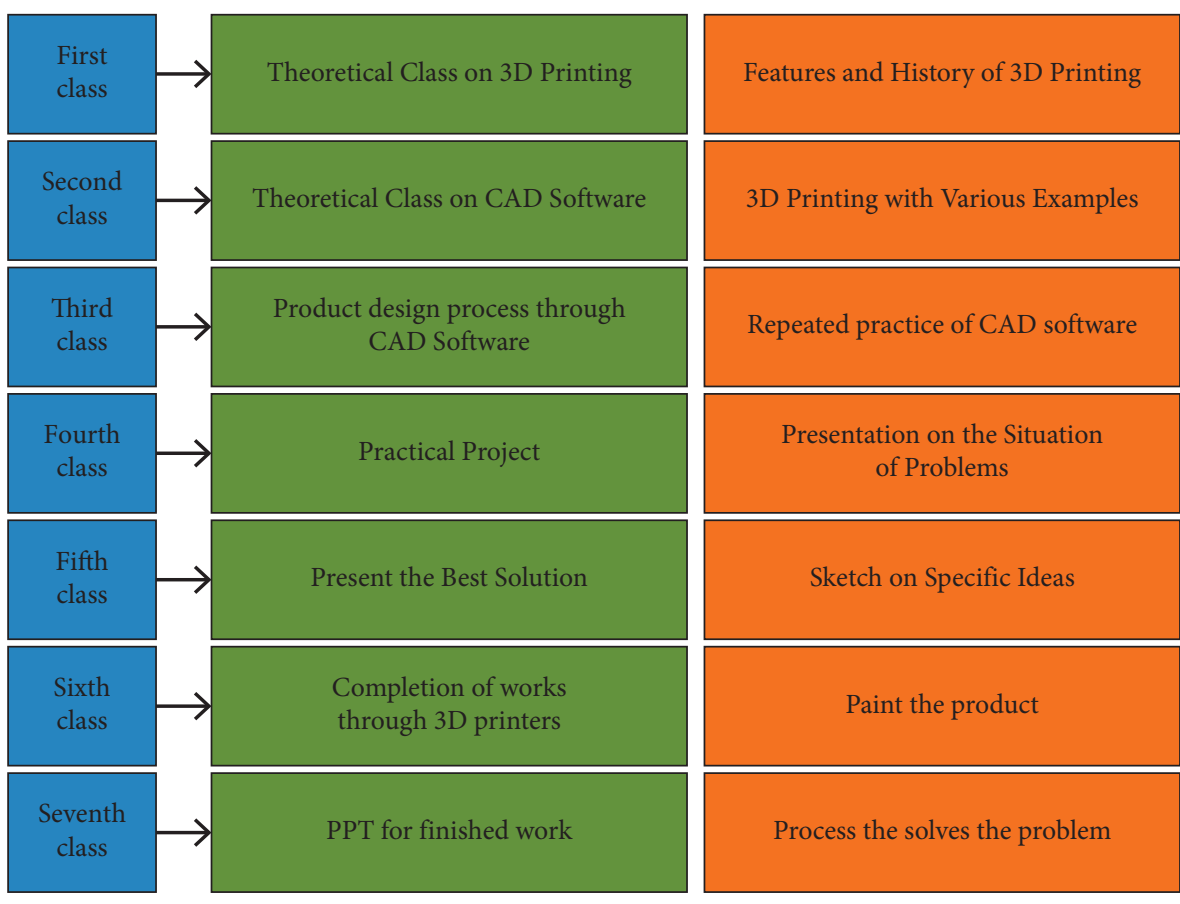

Process the solves the problem

FIGURE 4: 3D printing education course.

problems, students make PPTs and present problem situations. Then, under the teacher's guidance, students suggest a solution to the problem. In the fifth class, students express specific ideas through sketches. They also compare various methods and suggest the best solution. At this time, teachers may provide students with knowledge of design elements, such as colors and shapes. Also, according to teachers' guidance, students use CAD software based on sketches to create 3D files. In the sixth class, students complete their work directly through a 3D printer. In the seventh class, students present completed works according to the teacher's guidance. These presentations do not simply announce the outcome of the work but include the entire process from the planning stage to the outcome of the work. Students will be personally involved and experience the whole process of solving one problem. Through this process, students can develop creativity and problem-solving skills. In addition, these methods of education are taught autonomously to learners. Also, this class can be a convergence education that uses art and engineering together. In Figure 4, we present the proposed course and class structure.

5.4. 3D Printing Education Effect. The effects of 3D printing education are as follows. First, 3D printing education can increase space perception for students. Such education can have the effect of engineering education on students. Second, students can make their own design into the real products through 3D printers. This course can mostly motivate students than traditional learning. So, students will have more interest and degree of participation in learning with $3 \mathrm{D}$ printing technology. Third, this $3 \mathrm{D}$ printing curriculum can 
develop students' creativity. In this course, students think about the problem and autonomously find solution to it. Through this process, students can develop problem-solving skills and creativity. Fourth, students can develop a sense of cooperation by solving problems with others. In the future, the use of 3D printing will be common. In addition, 3D printing education will be provided in public education with the spread of low-cost 3D printers. Under these circumstances, it will be necessary to develop a curriculum that can maximize the effectiveness of 3D printing education. Generally, the mode of classes these days is the traditional way in which the teacher teaches the students; however, in the future, problem solving and creativity according to the changing society are more important than knowledge acquisition. This is hard to achieve by means of just teaching the contents of the curriculum. Along with other methods and tools that enhance the creativity of the students, 3D printing education is also an important aspect that could be used for improving creativity and to enable the students to adopt the problem-solving approach. Many educational institutes have adopted this teaching method such as Stanford University Graduate School of Design where this teaching method is called the design thinking teaching method. Besides that, this method also became the background for producing numerous entrepreneurs in Silicon Valley.

\section{Direction of Development in 3D Printing Education}

Currently, science and technology are advanced in public education, but the contents of education have not changed much from those of 50 years ago. Some of the current knowledge and classes may be not necessary in the future, which may lead to the loss of some majors and jobs someday. So, the current education is not appropriate for the situation of the times. To solve these problems, the government needs to invest and study new education. A representative example of new education is STEAM education, in which 3D printing education will be a key education. In $3 \mathrm{D}$ printing education, it is the process of identifying your own problems, finding solutions, and creating the final product. In this process, learners can gain a variety of knowledge. 3D printing technology will be a critical technology in the Fourth Industrial Revolution. In addition, various raw materials used in $3 \mathrm{D}$ printing technology will be developed. In the future, $3 \mathrm{D}$ printing technology can be used to make cars, machines, and buildings. In addition, everyone will be producers and consumers, and in this situation, 3D printing education is more important than anything else in public education. So, it will surely become future educators' central task.

\section{Conclusion}

In the recent era of the Fourth Industrial Revolution, 3D printing technology is important. The 3D printing education has recently drawn great social attention. Also, these $3 \mathrm{D}$ printing education courses should interest students and encourage satisfaction and learning outcomes in subjects.
So, this paper studied the specific methodology for $3 \mathrm{D}$ printing education. It is analyzed that this education method will help learners develop creativity and problem-solving skills. Future studies will also be required to prove that these methods are validated for their effectiveness in education.

\section{Data Availability}

No data were used to support this study.

\section{Conflicts of Interest}

The author declares that there are no potential conflicts of interest with respect to the research, authorship, and/or publication of this article.

\section{Acknowledgments}

This study was supported by the Research Funds for the Special Project of Online and Offline Hybrid Curriculum Construction (Architectural Design 1) of Nanjing University of Aeronautics and Astronautics (no. 20201140K). The author is grateful for the support.

\section{References}

[1] M. Farnicka and N. Serrano Diaz, "3D printing skills as a resource for the development of creativity in middle childhood,” Rocznik Lubuski, vol. 45, no. 1, pp. 123-134, 2019.

[2] H. G. Tomc and T. N. Kočevar, "Observation on creativity and spatial visualisation skills of graphic arts'students," in Proceedings of the 10th International Symposium on Graphic Engineering and Design, Novi Sad, November 2020.

[3] Y. Sung Kwan and Y. S. Kim, "Development of control board for coding education and convergence contents based on $3 \mathrm{D}$ printing," Journal of the Korea Convergence Society, vol. 9, no. 9, pp. 1-8, 2018.

[4] L. Shang Gu, J. Lee, J. Lee, and K. Park, "Mathematics, art and 3D-printing in STEAM education," Communications of Mathematical Education, vol. 29, no. 1, pp. 35-49, 2015.

[5] P. Keun, "Applications of 3D CAD and 3D printing in engineering design education," Journal of the Korean Society for Precision Engineering, vol. 31, no. 12, pp. 1085-1091, 2014.

[6] S. Kug Joo and K. Suk Rae, "A study on the curriculum by the process of actual use of 3D printer-focus on the college of design," Journal of Digital Convergence, vol. 14, no. 6, pp. 381-393, 2016.

[7] C. Hyung Shin and Yu Mi Ri, "A study on educational utilization of 3D printing: creative design model-based class," Journal of the Korean Association of Information Education, vol. 19, no. 2, pp. 167-174, 2015.

[8] S. Hyo Young and L. Hyang Eun, "Development and effectiveness of design education program using 3D printer," Design convergence study, vol. 17, no. 5, pp. 113-128, 2018.

[9] P. Spradley, Participant Observation, Holt, Rinehart \& Winston, New York, NY, USA, 1980.

[10] K. Duk Hoi, "The development of 3D printing primary education program using CAD SW," Journal of the Korean Association of Information Education, vol. 22, no. 5, pp. 557-564, 2018. 